\title{
Importance of Arterial Conduit Function Assessment in Chronic Congestive Heart Failure: Predictors of True Circulatory Decompensation for Optimal Timing of Mechanical Circulatory Support
}

\author{
Henryk Siniawski and Roland Hetzer \\ Department of Cardiothoracic and Vascular Surgery, \\ Deutsches Herzzentrum Berlin,
}

Germany

\section{Introduction}

Circulatory failure with no reaction to medical treatment requires urgent mechanical circulatory support to save the patient's life and to open up the way for broader medical options. When ventricular assist devices (VAD) must be urgently implanted in patients suffering not only from hemodynamic shock but from the disastrous consequences of prolonged hypoperfusinon of vital organs, they are associated with high mortality. Good early and late outcome can be anticipated by the principle "good patient, good outcome." In this sense a "good patient" for assist device implantation is one in whom the surgical procedure is undertaken in optimal time and not after the "zone of death" is reached, when the patient is suffering from multiorgan failure. Unfortunately optimal means of prognostic assessment of patients suffering from chronic circulatory failure are lacking. The available clinical guidelines are rather opened as a "road map" for the treatment until the treatment response is blunted and it is necessary to turn to the next step on this road.

From our viewpoint it is necessary to distinguish between diagnostic means of helping to assess or even predict the transition from chronic compensated to acutely decompensated heart failure and the assessment of various factors as predictors of mortality. In other words acute precipitants such as rising left ventricular filling pressure, pulmonary rales etc. and physical signs $\left[{ }^{[1]}\right.$ of congestive heart failure or even precipitants reflecting the conversion from a chronic compensated to a decompensated pathophysiological state do not necessarily help to set the indication for assist device implantation. These established factors today still lack reliability. The decompensation which "suddenly appears easy to treat" indicates that even acute worsening of chronic heart failure can be managed successfully by medical means. The important issue is to predict the risk of "true decompensation" (decompensation resistant to conventional treatment). The assessment of such factors is very valuable for estimating the optimal time-point for the implantation of mechanical circulatory support. Finding the optimal time also means that univentricular (usually left ventricular) support 
may be sufficient. In such cases the outcome is better than with extracorporeal support of both ventricles.

The goal of assessment of the "circulatory reserve" of the individual patient suffering from chronic circulatory failure is important; however the issue is very complicated. Until now such "factors" are unknown. More studies are needed to put together all known factors and, on the basis of statistical analysis, to extract "significant predictors influencing mortality." There are several problems that should be taken into account here.

Recent studies have suggested a multifactorial model containing many risk factors with statistical definition of their importance. The multifactorial risk model makes sense when the risk factors are correctly identified; otherwise, imprecise and misleading information can cloud the issue. The concept of setting a model with statistically prepared multirisk factors [2] as a "check list" is difficult to accept practically in clinical settings. Even separating the risks into precisely identified groups or goals (precipitating and predisposing) does not help clinicians to identify the best form of preventive intervention.

By critical examination of such a multifactorial model at least the following conclusions have to be drawn: The systolic function of the left ventricle is no longer of value in predicting survival of the patients when profound systolic dysfunction has occurred[3,4]. The dynamic development of congestive heart failure $\left(<12\right.$ month period) ${ }^{[5]}$ is an important factor; however in the less malignant course the number of episodes of decompensation is truly important. Laboratory tests (sodium[6], BNP[7], noradrenalin level[8]) can help to identify individual patients possibly characterized by low reserve compensation mechanisms. The function of the right heart chamber and pulmonary pressure are factors that predict mortality, but their practical value - their value for the prediction of the life expectancy - is limited[9,10]. Continuous ambulatory monitoring on the basis of telemetric data transmitted by miniaturized technology ${ }^{[11]}$ of the right-sided pressures ${ }^{[12]}$ (for example the value of pulmonary pressure at time of closure of the pulmonary valve corresponds to the left filling pressure) can be used to detect the transition to decompensation and are therefore valuable in predicting risk (SENSE-HF trial,[13] CLEPSYDRA[14]). Continuous telemetric hemodynamic monitoring does not assess the circulatory reserves directly but rather informs the clinician that the physiological balance of the hemodynamics inside the circulation as a whole system has broken down. New criteria that could precisely predict the clinical state of the patients are badly needed to make the surgical decision for optimal timing of mechanical support in chronically ill patients.

To understand the subject it is necessary to review the changing viewpoints on congestive heart failure. Congestive heart failure means chronic "circulatory failure" or "heart failure," caused, for example, by end-stage dilated cardiomyopathy.

\subsection{Historical resumé}

The quality of the arterial pulse was first described as early as the sixteenth century by the Polish physician Josephus Struthius in his work Sphygmicae artis (published in Basel in 1555). His knowledge of the pulse is still utilized today (e.g. the distinction between pulsus altus, parvus, rarus, celler and durus) and is used not only to diagnose a heart pathology such as mitral stenosis or aortic incompetence but also for heart failure staging. Traditional understanding of systolic heart failure was based on invasive investigation performed on the basis of animal studies performed in 1879 in Berlin, ${ }^{[15]}$ and diastolic function assessment 
was undertaken at the beginning of the last century.[16] Heart function was regarded as of central importance on the way to understanding the pathology of circulation since the beginning of the era of modern medicine but the importance of the "circulation" was also pointed out. The state of "heart failure" was described in Latin as "stadio circulatoria suffitientiae relativae" or "circulatioria in stadio insuffitiantiae," corresponding to the English expression, "congestive heart failure." Traditionally the meaning of "congestion" was reserved exclusively for the venous vascular bed. Nevertheless, in addition to myocardial failure, circulatory congestion was taken to be an important part of the phenomenon called "heart failure." The role of the "peripheral" circulation was seemingly forgotten.

Nowadays the vascular resistance, as the representation of the circulation and especially of conduit physiology, appears rather more as a hemodynamic result of the heart function and the arterial system response. It is usually defined as the force of opposition known as "resistance" but not as an active and important functional unit that cooperates actively with the heart. However, the researchers and physicians dealing with mechanical circulatory support are recognizing the problem of circulatory failure but rather only semantically, writing of "mechanical circulatory support in heart failure." Unfortunately this recognition is usually limited to expression and does not incorporate evidence-based medical factors of the importance of the circulation.

\subsection{Changing concept of the failing heart}

Reduction of left atrial loading conditions (preload) significantly alters the diastolic transmitral pressure relation and thus profoundly affects the Doppler flow velocity profile.[17] On the other hand the afterload also influences heart function. It is important to know how afterload affects preload in order to define the function of the extracardiac circulatory system. A.C. Guyton stated in 1955: "When a change occurs in the hemodynamics of the circulation system one cannot predict what will happen to the cardiac output unless to take in consideration both the effect of this change on the ability of the heart to pump blood and also on the tendency for blood to return to the heart from the blood vessels"[18]. This research produced a "volume pressure curve" of the systemic arterial and venous compartment which documents the interplay between venous pressure and volume in arterial and venous segments in dependence on stimulation or inhibition[19]. On the other hand the venous return influences the atrial pressure and consequently cardiac output (Guyton diagrams)[20], not to forget that venous return is regulated by the arterial system. Briefly, the pumping ability of the heart depends mostly on the venous return if the diseased heart is in stable condition after a destructive process has been healed. It should be stated that not the worsening of the failing myocardiac function but rather circulatory dysfunction during the chronic phase is the cause of worsening of the circulation as a whole. The monitoring of the arterial and venous compartment can help to define the hemodynamic condition and find predictors of the final event of decompensation.

The arterial part of the circulation (arterial conduit) is easy to access and, being situated between the venous compartment and heart function, not only has the passive function of conduction of the blood but is an active part of the circulation.

In normal human beings the heart can mobilize reserves so that the cardiac output can rise five times, for example from $6 \mathrm{l} / \mathrm{min}$ to $30 \mathrm{l} / \mathrm{min}$ in athletes. The severely diseased heart is 
hardly able to raise cardiac output by more than $10 \%$. The arterial tree can change the distribution of perfusion, depending on the acute need, to supply the more important organs and let other organs "hibernate." The physiological process known as "preconditioning" is responsible for the smoothly functioning economy of the body with a constant lack of oxygen. The circulation, and especially the arterial compartment, demonstrates abnormal vascular response to volume unloading when the heart is failing. [21] This implies that the arterial conduit is responsible for decompensation and is the key to stabilizing the circulation and to describing diagnostically its function and dysfunction. Virtually speaking there is the level of arterial conduit dysfunction beyond which compensation is not possible; below these levels "true" decompensation is only a matter of time. This concept of congestive heart failure is the clue to understanding the transition from the compensated to the decompensated state in patients suffering from heart failure.

\subsection{Arterial conduit function}

The left ventricle mechanically loads the systemic circulation in a pulsated manner. In abnormal LV function the circulation is supplied under special conditions determined by the autonomic properties of the vascular bed.

The influence of the arterial system on the heart as a pump in congestive heart failure is seldom presented in the literature; it is more often studied as its own unit of interest that responds to different deconditioning mechanisms.[22,23,24] Although the importance of pulse and blood pressure is always studied in hypertensive patients, the relation between the effect of the left chamber work, defined as stroke, and the arterial tree has not been adequately recognized. This may be the essential key to heart failure pathophysiology.

There are several methods of defining the active operation of the arterial conduit (large and small resistance arteries) interacting directly with the heart ejection. One of the simplest and most commonly applied to determine the stage of cooperation between the heart and the arterial system is invasive or non-invasive measurement of pressure in one of the branches of the arterial system. The pressure measured is the main criterion for diagnosis of acute heart failure (vasoactive shock). In recent years the importance of systolic pressure as a predictor of mortality in patients with acute and chronic ${ }^{[25]}$ forms of heart failure has been recalled. Low pressure in patients suffering from chronic forms of heart failure is recognized as a positive prognostic factor of mortality. However, the explanation of this phenomenon is based rather on a monotheory that failure of the heart (low cardiac output) may play a first role[26] (partial truth), but not that dysfunction of the arterial conduit - as an interactive organ - may also be involved in the state of "circulatory failure." Nevertheless there exists agreement that the result of interaction of the heart and arterial conduit - blood pressure - is an important prognostic factor for assessing the risk of mortality in acute and chronic forms of "heart failure."

Additional information on the circulatory state may be based on investigation of the relationship between cardiac output and blood pressure by a formula called the "cardiac power" [27] or "circulatory power" during peak exercise in stable patients.[28] The pumping power of the heart is determined as the product of cardiac output (simultaneously measured) and mean arterial pressure.

A study of patients suffering from acute forms of heart failure, especially those with ejection fraction of below $40 \%$, has documented that systolic blood pressure was linearly and inversely associated with mortality.[27] 


\subsubsection{Windkessel model}

Any part of the cardiovascular system, when it is compliant, possesses a volume reserve according to needs. The arterial windkessel model is based on a "system of tubes" as a representation of the arterial tree and allows analysis of the resistance and compliance of the arterial conduit.

\subsubsection{Pressure-flow analyses in the time domain}

Accurate non-invasively measured central arterial pressure and flow in large arteries available for investigation (e.g. the carotid artery) can be used for pressure-flow analysis. Using computational equipment to analyze both signals (pressure and flow) gives unique possibilities to assess interaction of the diseased heart and the arterial conduit. One method based on this principle is wave intensity (WI) measurement.

\section{Wave intensity}

The concept of wave intensity is based on simultaneous computerized analysis of the blood ejected into the arterial conduit, which causes the phenomenon of interaction of flow (the velocity of the stroke volume) with the flow mechanics inside the studied vessel and the interaction of pressure and compliance of the vessel. The simultaneous study of flow and pressure interaction enables WI assessment.

To understanding the whole concept it is necessary to review shortly the basic physiology of heart ejection as a function of the whole circulation. The early phase of ejection is characterized by a positive pressure gradient in the left ventricular outflow tract (LVOT) and a rise in both pressure and flow in the ascending aorta. After this phase the pressure still rises but the flow falls. During approximately the last third of ejection there is a negative pressure gradient in the LVOT and ejection persists, while flow and pressure fall until the aortic valve closes. Ejection occurs because the momentum of the blood shifts the last part of the stroke against higher pressure above the aortic valve.

It has to be remembered that the pressure difference between the LVOT and ascending aorta is negative late in systole (during $2^{\text {nd }}$ wave building). The ejection of blood into the aorta during this time results from the momentum of the ejected blood.[29] This phase is characterized by gentle relaxation of the myocardium[30] - leading to a smooth return of the muscle function from contraction to relaxation. The effect of this cooperation "gently" stops the back blood flow (before aortic valve closure) and again it should be stated that the relation of flow and pressure is directly related to the blood momentum but also to the diastolic quality of the heart muscle, which defines diastolic function of the heart before aortic valve closure (traditionally taken as the event signalling the relaxation period).

Invasive wave intensity (WI) index is well described by Parker et al.[31] and is primarily calculated from invasive parameters as the product of the derivatives of the simultaneously measured pressure and velocity inside the artery:

$$
\mathrm{WI}=(\mathrm{dP} / \mathrm{dt}) \cdot(\mathrm{dV} / \mathrm{dt})
$$

where $\mathrm{P}=$ pressure and $\mathrm{V}=$ flow.

The non-invasive simultaneous analysis of pressure change and flow signals sampled during short constant intervals $(5 \mathrm{~ms})$ can be used for real-time non-invasive WI (NWI) analysis. 
The waveform of carotid wall displacement (dU) closely corresponds to pressure change $(\mathrm{dP})$ in a carotid artery measured invasively with high correlation quotient (goodness of fit $\mathrm{r}^{2}=0.97$ ) and can be substituted for the invasively recorded pressure waveform. ${ }^{[32]}$ This study by Sugawara et al. has opened up the way to the assessment of NWI, because high fidelity pressure and flow signals are easily obtainable by ultrasonic investigation. Non-invasive wave intensity (NWI) is defined on the basis of echocardiography[33] (ALOKA Ultrasonic System, Japan). The formula for NWI is as follows:

$$
\mathrm{NWI}=(\mathrm{dU} / \mathrm{dt}) \cdot(\mathrm{dV} \text { Doppler } / \mathrm{dt})
$$

where $\mathrm{dU}=$ difference in displacement of carotid artery and $\mathrm{V}=$ flow velocity measured by Doppler.

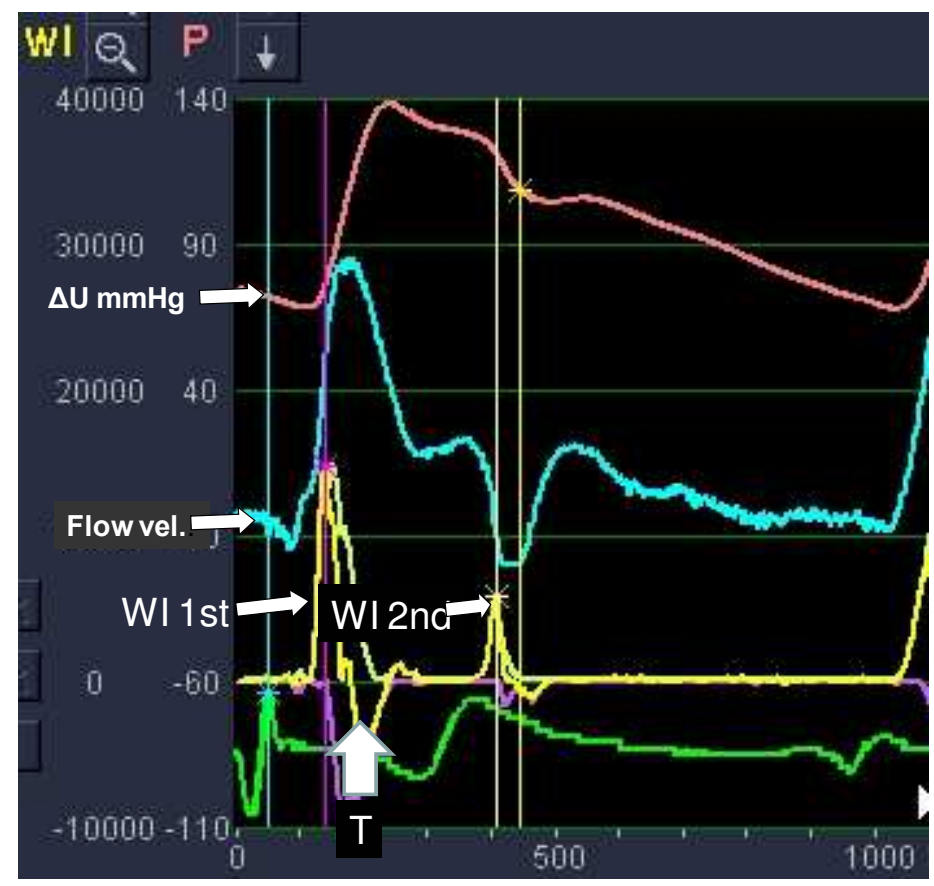

Fig. 1. The noninvasive WI index assessed in a normal subject. The yellow curve of WI consists of two peaks ( $1^{\text {st }}$ and $\left.2^{\text {nd }}\right)$. The $1^{\text {st }}$ peak is the "compression wave" and the $2^{\text {nd }}$ peak the "expansion" wave. The pressure (red curve) is marked " $\Delta \mathrm{U} \mathrm{mmHg}$ " and flow waveform (green curve) "flow vel.". The wave T is marked by a white arrow

The NWI index materializes as the curve consisting of two mathematically defined peaks (1st and $\left.2^{\text {nd }}\right)$. The $1^{\text {st }}$ peak is the "compression wave" and is mathematically positive as a product of two positive values of first derivatives of pressure and flow waveform as demonstrated mathematically (Fig. 1). The compression wave of the $1^{\text {st }}$ peak of WI describes the state of myocardial contractility of the LV in relation to the afterload. At the end of isovolumic contraction (which is the beginning of the $1^{\text {st }}$ peak) the LV pressure becomes equal to aortic diastolic pressure which indicates that the LV begins to challenge the afterload force.[34] The 
height of the peak is directly related to LV contractility and to stroke volume at a given afterload. This parameter reflects very tiny differences in ejection dynamics and stroke volume (at given/constant afterload) and can be used as a marker of circulatory reserves but also as a versatile marker in many clinical situations. The $2^{\text {nd }}$ peak is created during the negative pressure gradient in the LVOT and is influenced by the momentum of the blood ejected into the aorta. The value of momentum of blood ejection in the last phase of ejection is connected to relaxation of the LV. Simplifying the physiological dispute, this means that during ejection the blood is stopped by the gentle slowing of the LV ejection during the last part of ejection (when the pressure in the LV chamber is lower than in the aorta), which reflects the idea of relaxation of the LV myocardium, as was experimentally documented by Solomon. ${ }^{[35]}$ This explains why the $2^{\text {nd }}$ peak is related to the relaxation of the myocardium which begins before aortic valve closure.

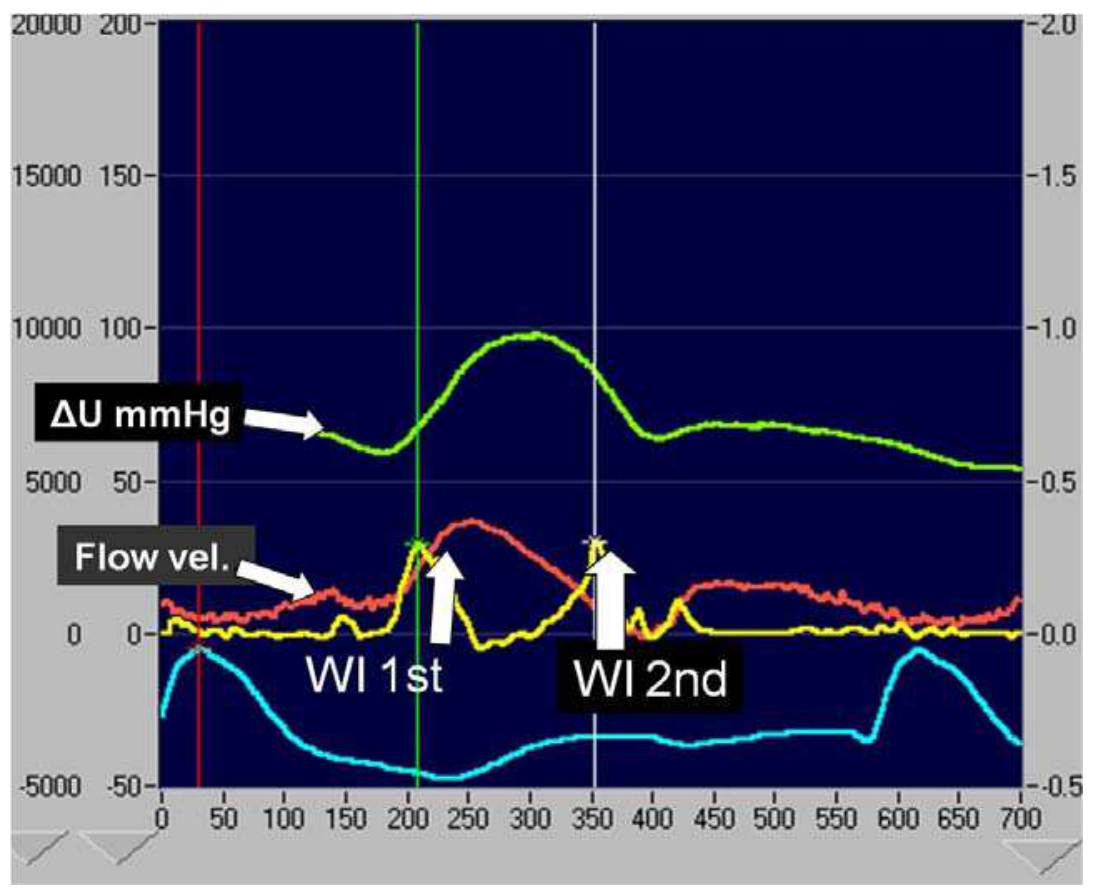

Fig. 2. The noninvasive WI (yellow curve) from a patient suffering from end-stage dilated cardiomyopathy during "true decompensation". Note that the green curve represents pressure and the red curve represents flow

Returning to the second phase of ejection, it is necessary to describe the negative part of WI appearing as the continuation of the $1^{\text {st }}$ peak and named negative $T$ wave (Fig. 1). The $T$ wave is formed by the negative product of pressure and flow $(\mathrm{dU} / \mathrm{dt}) \cdot(\mathrm{dV} / \mathrm{dt})$ where pressure is still rising and flow is diminishing (mixed mathematical factors reflected as negative product).

During WI investigation several parameters are obtainable: negative area T, arterial stiffness as beta value $(\beta)$, diameter of the artery studied, minimal and maximal flow in the artery 
and dynamic changes in real time of several other parameters. The $\mathrm{T}$ wave was not found to have prognostic importance in our studies.

The $2^{\text {nd }}$ peak of WI ("expansion wave") is calculated in the same way as the $1^{\text {st }}$ peak, which means that it is the result of algebraically calculated pressure and flow inside the vessel after ejection. While both curves (pressure and flow) in this phase are negative, algebraically their derivates produce a positive $2^{\text {nd }}$ peak of WI. In general this peak defines diastolic function of the heart (active relaxation of the myocardium in systole) and the diastolic function of the conduit (elastic properties, filling of the conduit, which is similar to LV filling). The $2^{\text {nd }}$ peak is usually smaller than the $1^{\text {st }}$ but in pulsus alternans or in a situation of passively overfilled arterial conduit (with any kind of rotary pump support) it can be higher than the $1^{\text {st }}$ peak if the heart possesses native ejection.

\subsection{Human studies}

\subsubsection{Influence of alternant beat (reduced contractility) on wave intensity (type A pathology of myocardial failure)}

The pathophysiology of pulsus alternans is diverse and there are several theories that are used to explain this phenomenon. Although description of all these theories is not necessary for this purpose, it is important to note that the majority of considerations are based on myocardial, electrical and hemodynamic functional components. The myocardial theory is based on the alteration of diastolic prosperities of myocytes of the diseased heart[36,37], whereas the electrical alternans theory[38] is based on the primary alteration of electrical stimulation, secondarily influencing myocardial reaction. The hemodynamic theory explains "weak beats" on the basis of worse filling of the chamber (loading conditions) and alteration of the Frank-Starling curve. Independently of different theories that could explain the pathology of pulsus alternans the one beat is strong ("normal" for studied individual) and the second is weak. In other words the stroke volume is alternately normal and smaller, causing normal pulse quality, and the second beat is weak and recognizable on the blood pressure curve or by studying the pulse in any other way. It is well documented that pressure in late diastole rises more slowly in the weak beat, which has to interpreted by an alteration in diastolic compliance ${ }^{[39]}$.

Figures $3 \mathrm{~A}$ and $\mathrm{B}$ demonstrate WI applied in an ambulatory patient suffering from DCM at the stage of NYHA III and having pulsus alternans (3B). WI peaks from "strong" (3A) and "weak" (3B) beats identify the hemodynamics of the composite of the heart and arterial conduit in this individual. The 1st (Fig. 3A, white arrow) and second WI peak (Fig. 3A, red arrow of the "strong beat" are typical findings in heart failure patients. The $1^{\text {st }}$ WI peak is small but the $2^{\text {nd }}$ peak is relatively higher than in normal individuals and is responsible for the quotient of relation of the $1^{\text {st }}$ to the $2^{\text {nd }}$ peak being 2:1 (1st 3441 to $\left.2^{\text {nd }} 1834 \mathrm{mmHg}^{*} \mathrm{~s}^{3}\right)$, whereas in normal persons it is usually 6:1.

The second beat is "weak" and is produced by suboptimal stroke volume (Fig. 3B) influencing the pulse curve peak $(\mathrm{P})$ which is smaller and rises more slowly. The simultaneously recorded flow (F) curve also rises more slowly, so that the $1^{\text {st }}$ peak of WI as a product of the derivatives of pressure/flow $(\mathrm{dU} / \mathrm{dt}) \cdot(\mathrm{dV} / \mathrm{dt})$ is reduced to $50 \%$ of the previous strong beat. The $2^{\text {nd }}$ peak is preserved and both peaks are at the level of $1800 \mathrm{mmHg}^{*} \mathrm{~s}^{3}$. The high $2^{\text {nd }}$ peak of WI is exemplified by a negative and sharp fall in the product of the derivatives pressure and flow recorded simultaneously. An explanation of the reduction of the $1^{\text {st }}$ and preservation of the $2^{\text {nd }}$ 
peak of WI helps us to understand the importance of WI as a tool defining hydraulic cooperation of the arterial conduit and the heart. The lower and less "dynamic" the early ejection phase, the lower the $1^{\text {st }}$ peak for given compliance of the conduit is. The $2^{\text {nd }}$ peak of WI illustrates and defines the level of the conduit filling (see next subsection), the value of ejected blood momentum during the $3^{\text {rd }}$ phase of ejection, and compliance of the chamber at the end of systole before aortic valve closure. This $2^{\text {nd }}$ peak is inversely related to diastolic compliance of the LV and inversely related to the state of filling of the conduit (see below).

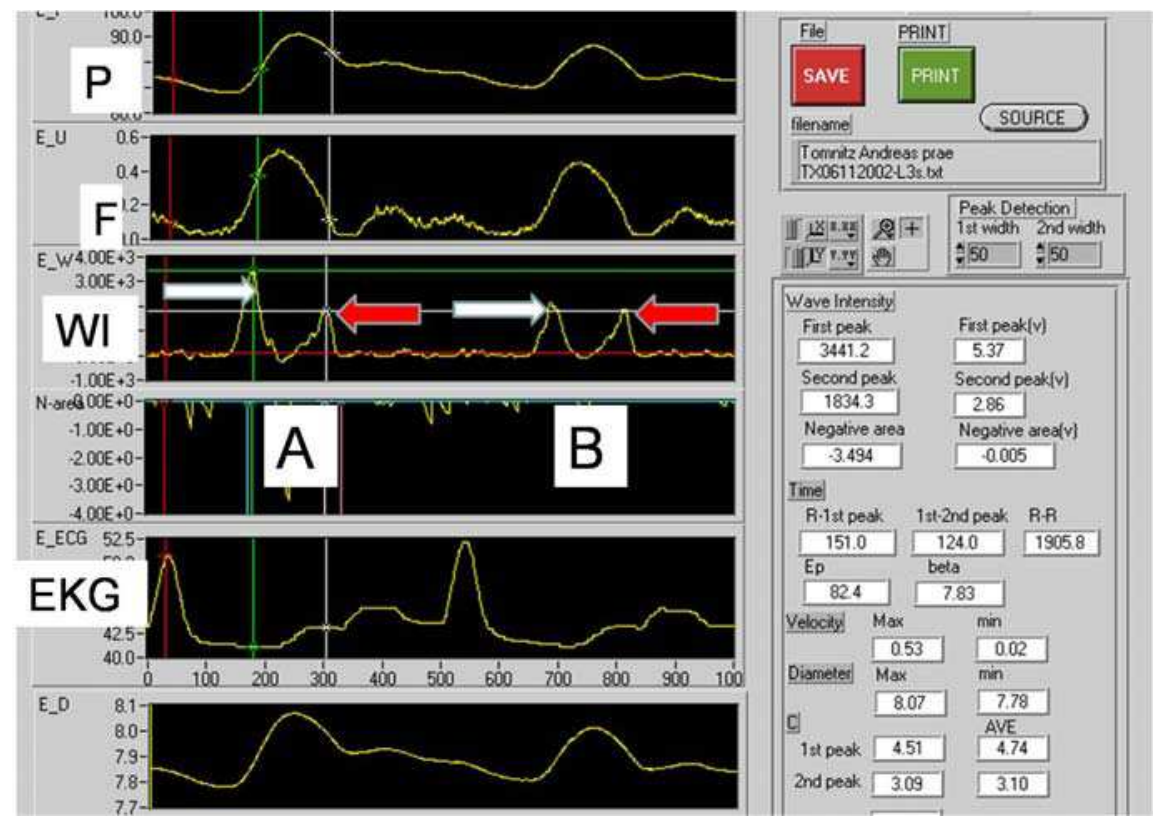

Fig. 3. Noninvasive WI in a patient suffering from end-stage dilative cardiomyopathy who has pulsus alternans. A: strong beat; $\mathrm{B}$ : weak beat. $\mathrm{P}=$ pressure curve. $\mathrm{F}=$ flow curve. White arrow $1^{\text {st }}$ and red arrow $2^{\text {nd }}$ peak of WI. EKG= electrocardiogram

\subsubsection{Mixed pathology of arterial volume overloading and systolic heart dysfunction influences wave intensity (type B pathology)}

The clinical picture of congestive heart failure when arterial congestion is present can be illustrated by the case of a patient who suffered from acute myocardial infarction complicated by cardiogenic shock 7 days after successful revascularization during Impella mechanical circulatory support (Fig. 4A). This is a schematic representation of arterial filling during Impella support with flow of $3.5 \mathrm{l} / \mathrm{min}$ and native stroke volume of the heart of only $20 \mathrm{ml}$. Because the LV chamber is partially unloaded (filling pressure only $7 \mathrm{mmHg}$ ) the stroke volume is low and reaches only the level of $20 \mathrm{ml}$. The 1st peak is low (approx. 5500 $\mathrm{mmHg}^{*} \mathrm{~s}^{3}$ ) and produced by slowly rising pressure and simultaneous slowly rising flow curve during the first phase of systole (Fig. 5A). The 2nd peak is high (approx. 8800 $\mathrm{mmHg}^{*} \mathrm{~s}^{3}$ ) and produced by sharply falling pressure and flow (even below the zero line) during the last phase of systole. The diameter of the artery was significantly larger than 
during reduced Impella flow $(6.93 \pm 1.39$ vs. $6.45 \pm 1.97 \mathrm{~mm}$ respectively, $\mathrm{p}=0.003)$. Reduced systolic function of the diseased heart and unloading defined by the Starling principle reflect type 1 pathology ("weak" beat of pulsus alternans) and is responsible for low $1^{\text {st }}$ peak. The $2^{\text {nd }}$ peak of WI is not proportionally higher, reflecting severe diastolic dysfunction and arterial overloading. During the procedure of weaning from Impella there are important alterations in the loading conditions of the heart and arterial conduit (Fig. 4B). In this stage, when the pump did not significantly fill the arterial conduit $(0.2 \mathrm{l} / \mathrm{min})$ the patient was treated with high doses of epinephrine and the heart was driven by adequate filling for this state of disease (PCP $18 \mathrm{mmHg}$ ), producing stroke volume of $40 \mathrm{ml}$.

The value and relations of peaks during spontaneous heart function (with maximal Impella support the heart did not possess sufficient filling to eject) is presented in Fig. 5B. The $1^{\text {st }}$ peak was high (approx. 21,000 $\mathrm{mmHg}^{*} \mathrm{~s}^{3}$.) after medical support and the second was higher than normal (approx. $3800 \mathrm{mmHg}^{*} \mathrm{~s}^{3}$ ). High $2^{\text {nd }}$ peak can be explained by high negative flow in the conduit and a rapid fall in the pressure curve before aortic valve closure. These phenomena are mainly due to rapid vanishing of the value of momentum of blood, reflecting reduced compliance of the heart muscle after infarction. The $2^{\text {nd }}$ peak is inversely related to the diastolic compliance of the LV (and all parameters influencing myocardial compliance). Again this experimental study demonstrates that $1^{\text {st }}$ peak is related to systolic function of the heart in relation to arterial conduit function. The $2^{\text {nd }}$ peak defines diastolic function of the LV chamber and the filling state of the arterial conduit.
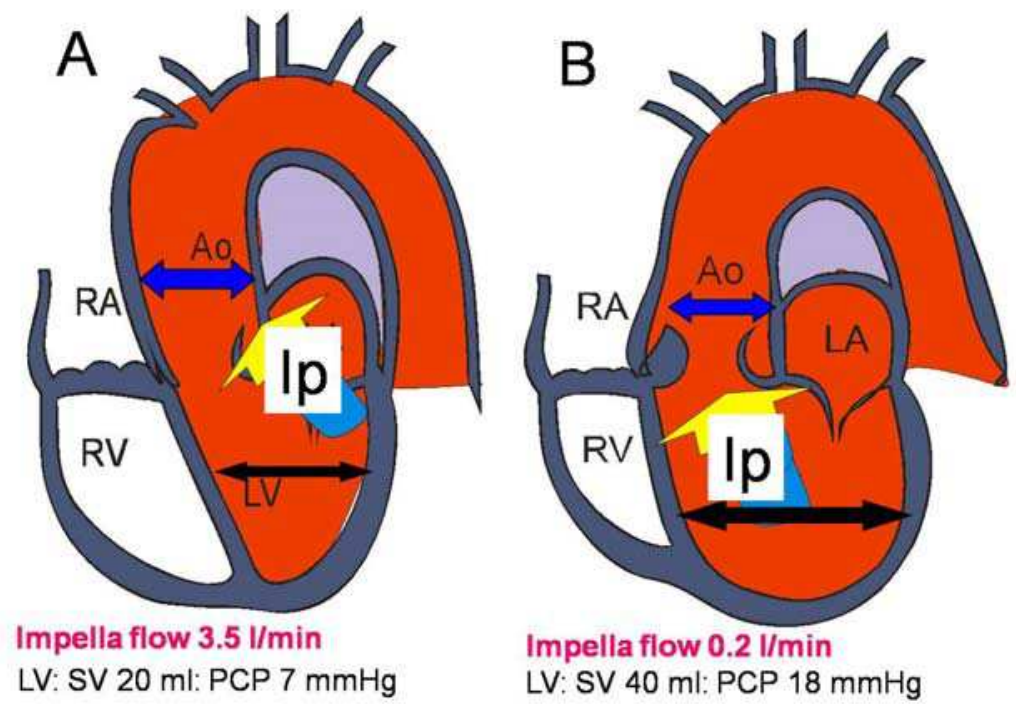

Fig. 4. Schematic drawing of the heart chambers and aorta (Ao) during different stages of seventh day Impella support in a patient following successful surgical revascularization, suffering from heart infarction complicated by cardiogenic shock. A: Impella (Ip) low 3.5 1/min (stage A); B: Impella flow (Ip) $0.21 / \mathrm{min}$ (stage B). Blue arrows indicate aortic dimension (Ao) dependent on Impella support. Black arrows indicate LV dimension dependent on Impella support. LA = left atrium, RA = right atrium, RV = right ventricle, $\mathrm{SV}=$ stroke volume, $\mathrm{PCP}=$ pulmonary capillary pressure 
Physiological cooperation between the chambers and the arterial conduit means that under a given filling pressure of both sides adequate systolic performance is maintained in changing circumstances (resistance, preload, afterload) which can be monitored noninvasively by WI.

One can hypothesize that these two types of pathology (A, primary myocardial dysfunction and $\mathrm{B}$, myocardial dysfunction and volume shift into the arterial conduit, responsible for congestion) are probably the icons of the daily clinical situations in patients suffering from end-stage congestive heart failure.

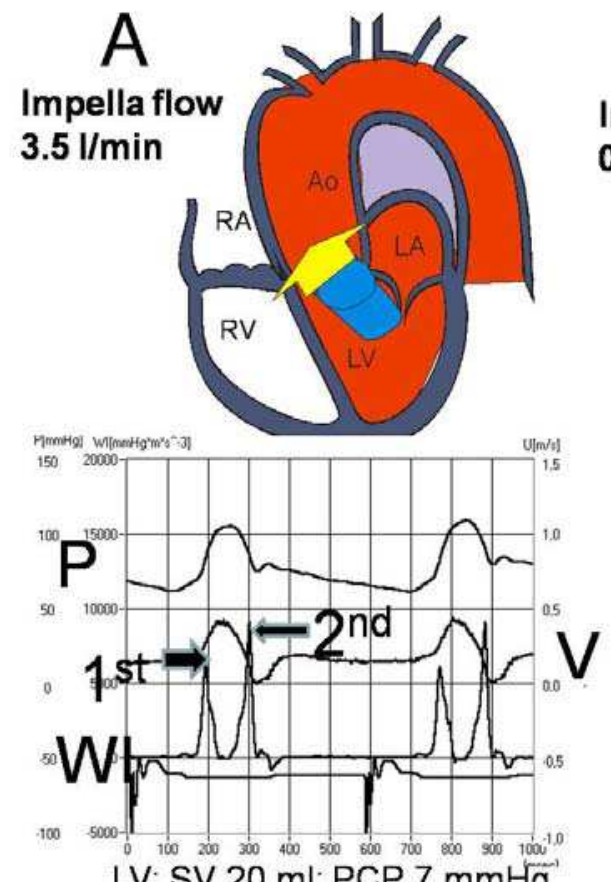

LV: SV $20 \mathrm{ml}$ : PCP $7 \mathrm{mmH}$

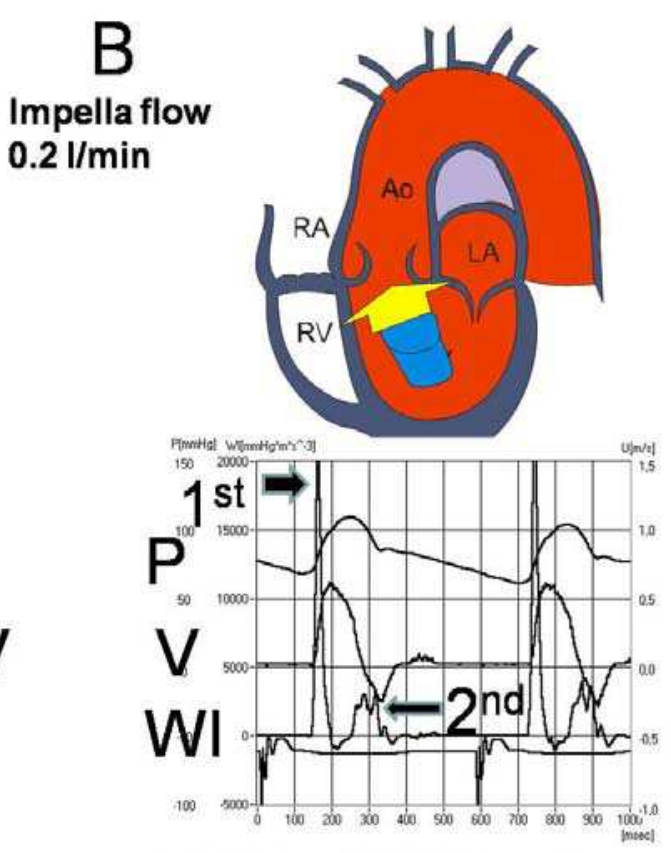

LV: SV $40 \mathrm{ml}$ PCP $18 \mathrm{mmHg}$

Fig. 5. The noninvasive WI $1^{\text {st }}$ and $2^{\text {nd }}$ peak (WI curve) assessed in the patient represented in Fig. 4, during stage A and B of Impella support. The scale is the same for A and B. $\mathrm{P}=$ pressure, $\mathrm{V}=$ flow, $\mathrm{SV}=$ stroke volume, $\mathrm{PCP}=$ pulmonary capillary pressure

\subsubsection{Effect of posture on wave intensity}

WI studies in humans suffering from circulatory failure are limited to a small number of centers.[40] In 2001 we first studied 31 patients suffering from end stage DCM[41] to assess circulatory reserves by utilizing a simple tilting test moving patients from supine to upright position. When DCM patients moved from supine to upright position, the filling of the venous bed was reduced (the overdistended jugular vein was collapsed) and filling of the heart chambers was therefore also reduced. Changed preload and afterload forces influenced the mitral filling pattern of the failing myocardium as well, as recorded by pulsed Doppler. The E wave (early filling or spontaneous filling) was significantly reduced $(0.7 \pm 0.22$ vs $0.4 \pm 0.19 \mathrm{~m} / \mathrm{s}, \mathrm{p}=0.001)$ and the A wave (atrial kick) was unchanged $(0.5 \pm 0.15$ 
$\mathrm{m} / \mathrm{s}$ vs $0.5 \pm 0.10$ ). This alteration significantly influences in a negative manner the stroke volume $(\mathrm{p}=0.05)$ but not WI parameters. The $1^{\text {st }}$ and $2^{\text {nd }}$ peak were not significantly higher in standing than in supine position (1st $4606 \pm 2283$ vs $5405 \pm 2432$ and $2^{\text {nd }} 1483 \pm 675$ vs $2002 \pm 726$ $\mathrm{mmHg}^{*} \mathrm{~s}^{3}$, both ns). The conclusion should be drawn that in patients suffering from chronic systolic and diastolic myocardial failure the acutely provoked hemodynamic imbalance of preload and afterload influences SV negatively, but this alteration was corrected by mechanical cooperation of the arterial conduit to keep adequate conditions in the circulation system. Therefore the wave intensity marker is helpful by providing information not only about LV systolic function but also about the mechanoelastic prosperities of the arterial system integrated with the elastic prosperities of the myocardium responsible for hemodynamic homeostasis.

\subsubsection{Wave intensity as a prognostic marker}

The next study at the Deutsches Herzzentrum Berlin (DHZB, German Heart Institute Berlin) was performed in a prospective manner to establish the utility of WI as a predictor of life

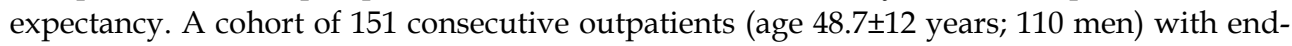
stage DCM was prospectively studied. The follow-up period of patients was $31 \pm 8$ months. End-points were death, life-saving circulatory support, and urgent transplantation.

During the follow-up 44 patients were lost; there were 15 cardiac deaths (10\%), life-saving ventricular assist device implantation in 10 (6.6\%) and transplantation in 19 (12.7\%). The most accurate predisposing factor for events (death, assist device implantation and urgent transplantation) in ambulatory patients was low $1^{\text {st }}$ peak (OR 45.6, CI 14.5-143.3, p<0.001) (Fig. 1). The "cut-off value" for $1^{\text {st }}$ peak assessed on the basis of our study was set at the

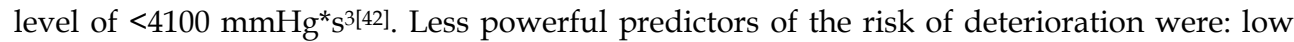
quotient of $1^{\text {st }}$ to $2^{\text {nd }}$ peak relation, left sided filling pressure $(\mathrm{PCP})$, diastolic PAP and E/A mitral wave ratio ( $p=0.05$ for all). Left ventricular ejection fraction (LVEF) and LV diameter did not show statistical significance for this purpose.

Figure 6 shows the event-free cumulative survival of ambulatory patients $(n=151)$. This curve does not represent a pure survival curve because patients who were removed from this curve do not represent those who died, while this group includes those who were saved by transplantation or VAD implantation as well as those who died. Patients accepted in this way and regarded as "event free" represent those who were hemodynamically stable. In other words, the group of patients designated "event positive" were lost for the purposes of our study not only because of death but also because of hemodynamic instability or hemodynamic and clinical worsening; these patients could not be stabilized with medical means but required assist device implantation or urgent transplantation.

\section{Discussion}

The usual and until now most plausible explanation for unexpected or unpredicted worsening (transition) into "true decompensation" was based on primary systolic or diastolic myocardial failure[43,44]. In the list of probable predictors the arterial part of the circulation has been ignored as a possibly important issue where "unknown" factors could be hidden. This has led to limited interest and little evidence-based research regarding the function of the arterial system in the presence of the "failing heart"; however, the concept of 
a causal relation between the heart and arterial conduit failure ${ }^{[45]}$ is an important topic. It should be kept in mind that the arterial tree functions as a "conductor" and plays a vital role as an active transmitter of blood to the peripheral tissue. The reactivity of the arterial system to any kind of physiological stimulation is well known from animal studies and can negatively influence study results.[46] However, patients suffering from congestive heart failure in general and especially from the advanced stages of the disease are very stable (blunted reactivity) and do not demonstrate variability of WI parameters from beat to beat. This method was validated and demonstrated good reproducibility in human beings.[47]

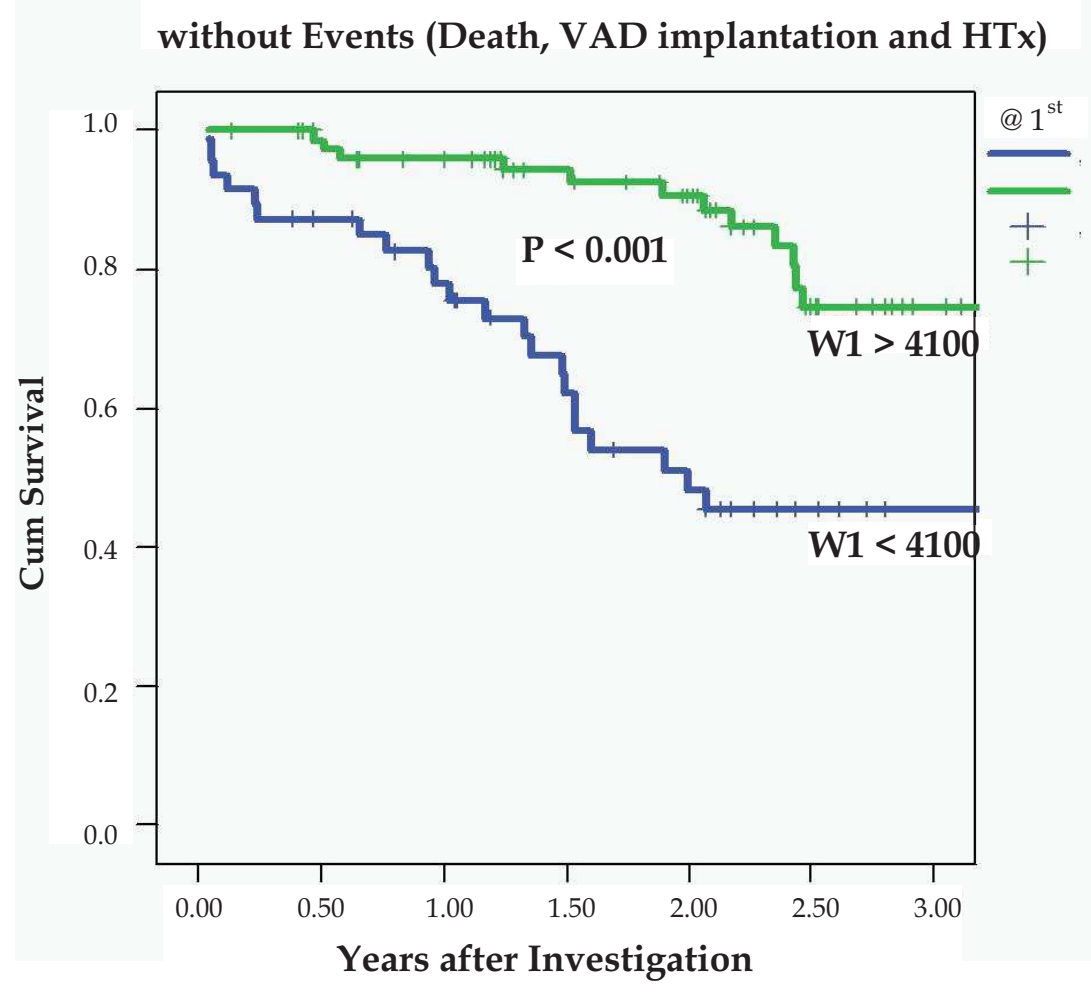

Fig. 6. "Event free" cumulative survival for ambulatory patients $(n=151)$ divided into two groups according to the development of $1^{\text {st }}$ peak WI. Survival of patients possessing WI $1^{\text {st }}$ peak $>4100 \mathrm{mmHg}^{*} \mathrm{~s}^{3}$ (green curve); survival with the peak $<4100 \mathrm{mmHg}^{*} \mathrm{~s}^{3}$ (blue curve). The cut-off value of $4100 \mathrm{mmHg}^{*} \mathrm{~s}^{3}$ was established empirically by studying the group of patients during "true decompensation"

\subsection{Wave intensity parameters studied in carotid artery as predictors of hemodynamic deterioration}

Although NWI was assessed in the carotid artery it defines the cooperation of the heart with the arterial conduit (aorta and arterial system) as a whole and not exclusively the arterial system of the heart. This is the law of "connected compartments" (vessels). Our results 
documented the true importance of WI assessment in defining lack of circulatory reserves, although for patients in whom heart dysfunction is present the "extracardiac" factors may play an important role in driving the patient to progressive decompensation. It has been hypothesized by others that elevated filling pressure may secondarily cause heart dysfunction but not always be the result of the loss of myocardial performance ${ }^{[48]}$. Changes in afterload are common physiological reactions of the highly sensitive arterial segment of circulation. The left ventricle "meets" directly the afterload at the end of isovolumic contraction, when the left ventricular pressure becomes equal to the aortic diastolic pressure, as stated by $\mathrm{M}$. Katz. The pressure-volume relationship is strongly dependent on afterload. Increasing the afterload reduces the stroke volume of the diseased heart by increasing the pressure throughout ejection. On the contrary, decreasing the afterload reduces left ventricular pressure during ejection and increases stroke volume. ${ }^{[49]}$ In other words overloading of the arterial conduit (e.g. by volume shift or sympathetic stimulation) can lead to backward LV loading above the tolerance of the diseased heart, causing smaller stroke volume. This diminution of stroke volume is difficult to assess but WI $1^{\text {st }}$ peak reduction is significant. Hypervolemic episodes which lead to an afterload rise above the control ability of the diseased myocardium, do not necessarily mean simple volume overload but may represent an inter-compartment volume shift inside the circulation.[50] Newly published data supports the hypothesis that "hypervolemic episodes" are produced by volume shift in patients suffering from chronic heart failure rather than by simple external "over-supplementation." The study by Zile and coworkers[12] documented that the transition from compensation to decompensation in a group of patients suffering from chronic systolic heart failure was not bound with body weight gain and that the development of pulmonary edema was due to volume shift from one compartment to the other. Whether it was a backward or forward shift is a matter of debate. Failing interaction of the heart chambers caused by blunted vasoreflexes can cause pulmonary edema. If the right atrial filling alters in the sense that the $\mathrm{RV}$ increases stroke volume by only $5 \mathrm{ml}$ per beat, then the LV chamber attempts to increase the stroke volume also but, if this is not possible, after 100 beats the lungs will be overloaded. On the other hand rising afterload of the LV can cause LV depression which is described as "backward" failure. The rise in afterload does not necessarily need to be connected to an arterial pressure rise but may be related to volume shift in a mechanism of reduced peripheral perfusion, as partially documented in our type B failure.

\section{Conclusion}

It can be hypothetically stated that heart disease is responsible for the physiological state known as heart failure but that worsening of the heart failure or recompensation should be considered dysfunction of the arterial segment of the cardiocirculation.

In general these theories support the explanation of the results of our study that cooperation between the failing heart and the arterial conduit can be an important and until recently "unknown factor" for outcome prediction in patients suffering from congestive heart failure. As we assumed, some research indicates strongly that diastolic function of the heart may be reflected in the 2nd peak[51]; this could also be interpreted as relaxation dysfunction of the LV myocardium, as we discussed in the description of "type B" pathology. In this respect WI (2nd peak) defines the diastolic function of the heart during the early phase of relaxation. However, in our study the $1^{\text {st }}$ peak was found to be the most significant $(\mathrm{p}<0.001)$ prognostic 
factor of final hemodynamic deterioration, and this factor can be utilized in surgical decision-making for assist device implantation.

We conclude that the new ventricular-arterial coupling WI parameters assess heart-arterial conduit function. The study of arterial conduit function is promising for the prognostic assessment of patients suffering from heart failure and can help to define the optimal timing for mechanical circulatory support.

Literally the WI $1^{\text {st }}$ peak can potentially be used to distinguish patients at high risk for true deterioration and death. High $2^{\text {nd }}$ peak is related to severe diastolic heart failure and overvolumed arterial bed during the conversion from compensation to decompensation.

\section{Acknowledgment}

The authors thank Anne M. Gale for editorial assistance.

\section{References}

[1] Stevenson LW, Perloff JK. The limited reliability of physical signs for estimating hemodynamics in chronic heart failure. JAMA 1989;261:884-8

[2] Lee DS, Vasan RS. Novel markers for heart failure diagnosis and prognosis. Curr Opin Cardiol. 2005;20:201-10

[3] Stevenson WG, Stevenson LW, Middlekauff HR, Fonarow GC, Hamilton MA, Woo MA, Saxon LA, Natterson PD, Steimle A., Walden JA, Tillish JH. Improving survival for patients with advanced heart failure: A study of 737 consecutive patients. J Am Coll Cardiol 1955;26:1417-23

[4] Deng MC, De Meester JM, Smits JM, Heinecke J. Effect of receiving a heart transplant:Analysis of a national cohort entered on to a waiting list, stratified by heart failure severity. BMJ 2000;321:540-5

[5] Rieckenbacher PR, Trindade PT, Haywood GA, Vagelos RH, Schroeder JS, Willson K, Prikazsky L, Fowler, MB. Transplant candidates with severe left ventricular dysfunction managed with medical treatment: Characteristics and survival. J Am Coll Cardiol 1996;27:1192-7

[6] Lee WH, Packer M. Prognostic importance of serum sodium concentration and its modification by converting-enzyme inhibition in patients with severe chronic heart failure. Circulation, Feb 1986; 73: 257-67

[7] Abramson BL, Ando S, Notarius CF,. Rongen GA, Floras JS. Effect of atrial natriuretic peptide on muscle sympathetic activity and its reflex control in human heart failure. Circulation 1999; 99(14): 1810-15

[8] Azevedo ER, Newton GE, Floras JS, Parker D. Reducing cardiac filling pressure lowers norepinephrine spillover in patients with chronic heart failure. Circulation 2000;101(17): 2053-59

[9] Alpert JS., The effect of right ventricular dysfunction on left ventricular form and function. Chest.2001;119/6:1632-33

[10] Salvo TG, Mathier M, Semigran MJ, Dec GW. Preserved right ventricular ejection fraction predicts exercise capacity and survival in advanced heart failure. J Am Coll Cardiol 1955;25:1143-53

[11] Hassan A, Paul V. Telemonitoring in heart failure. E Heart J doi:1093/eurheart/ehr005 
[12] Zile MR, Bennett TD, St. John Sutton M, Yong KC, Adamson PB., Aaron MF, Aranda JM Jr et al. Transition from chronic compensated to acute decompensated heart failure: Pathophysiological insights obtained from continuous monitoring of intracardiac pressures. Circulation, 2008; 118: 1433-41

[13] Conraads VM, Tavazzi L, Santini M, Oliva F, Gerritse B, Yu C-M. Cowie MR. Sensitivity and positive predictive value of implantable intrathoracic impedance monitoring as a predictor of heart failure hospitalizations: the SENSE-HF trial. Eur Heart J, February 28, 2011; (2011) ehr050v1

[14] Auricchio A Brugada J, Ellenbogen KA, Gold MR, Leyv F, CLEPSYDRA investigators. Assessment of a novel device-based diagnostic algorithm to monitor patient status in moderate-to-severe heart failure: rationale and design of the CLEPSYDRA study. Eur J Heart Fail 2010;12(12):1363-71

[15] Roy CS. Journal of Physiology, 1879, i, pp. 470, 496

[16] Henderson, Y. The volume curve of the ventricles of the mammalian heart, and the significance of this curve in respect to the mechanics of the heart beat and the filling of the ventricles. Am. J. Physiol. 1906;16:325

[17] Courtois M, Vered Z, Barzilai B, Ricciotti NA, Perez JE, Ludbrook PA.. The transmitral pressure-flow velocity relation effect of abrupt preload reduction. Circulation 1988;78:1459-68

[18] Guyton AC. Determination of cardiac output by equating venous return curves with cardiac response curves. Physiol Rev 1955;35:123-29

[19] Guyton AC, Hall JE. Textbook of Medical Physiology. Vascular Distensibility and Functions of the Arterial and Venous Systems. Ch 15. (12 th ed.). Saunders Elsvier, 2011, p. 168

[20] GuytonAC Hall JE. Textbook of Medical Physiology. Cardiac Muscle; The Heart as a Pump and Function of the Heart Valves. Ch 9. (12th ed.). Saunders Elsvier, 2011, p. 101-113

[21] Atherton JJ, Thomson HL, Moore TD, Wright KN, Muehle GWF, Fitzpatrick E, Frenneaux MP. Diastolic ventricular interaction: A possible mechanism for abnormal vascular responses during volume unloading in heart failure. Circulation 1997;96:4273-79

[22] Kubo SH, Cody RJ. Circulatory autoregulation in chronic congestive heart failure: responses to head-up tilt in 41 patients. Am J Cardiol. 1983;52:521-28

[23] Thomson HL, Wright K, Frenneaux M. Baroreflex sensitivity in patients with vasovagal syncope. Circulation. 1997;95:395-400

[24] Thorén P. Characteristics of left ventricular receptors with non-medullated vagal afferents in cats. Circ Res. 1977;40:415-21

[25] Raphael CE, Whinnett ZI, Davies JE, Fontana M, Ferenczi EA, Manisty CH, Mayet J, Francis DP. Quantifying the paradoxical effect of higher systolic blood pressure on mortality in chronic heart failure. Heart 2009;95:56-62

[26] Pfeffer MA. Blood pressure in heart failure: a love-hate relationship. J Am Coll Cardiol 2007;49:40-42

[27] Nunez J, Nunez E, Fonarow GC, Sanchis J,. Bodi V, Bertomeu-Gonzalez V, Minana G et al. Differential prognostic effect of systolic blood pressure on mortality according to left-ventricular function in patients with acute heart failure. Eur J Heart Fail 2010; 12(1): 38-44 
[28] Cohen-Solal A, Tabet JY, Logeart D, Bourgoin P, Tokmakova M, Dahan M. A noninvasively determined surrogate of cardiac power ('circulatory power') at peak exercise is a powerful prognostic factor in chronic heart failure. Eur Heart J 2002;23:806-14

[29] Noble MI. The contribution of blood momentum to left ventricular ejection in the dog. Circ Res 1968;23:663-70

[30] Spencer MP, Griess FC. Dynamics of ventricular ejection. Circ Res 1962;10: 274

[31] Parker KH., Jones CJH., Forward and backward running waves in the arteries: Analysis using the method of characteristics. J Bimech Eng 1990;112:322-26

[32] Sugawara M, Niki K, Furuhata H, Ohnishi S, Suzuki S. Relationship between pressure and diameter of the carotid artery in humans. Heart Vessels 2000;15:49-51

[33] Harada A, Okada T, Sugawara M, Niki K Development of a non-invasive real-time measurement system of wave intensity. Proceedings of IEEE Ultrasonics Symposium 2000:1517-20

[34] Katz AM. The working heart. In: Katz AM. Physiology of the Heart. Lippincott Williams and Wilkins, fifth edition 2011, p. 328

[35] Solomon S.B., Nikolic S.D., Frater R:W., Yellin E.L. Contraction-relaxation coupling: determination of the onset of diastole. Am. J. Physiol. 1999;277:H23-H27

[36] Lendrum B, Feinberg H, Boyd E, Katz LN. Rhythm effects on contractility of the beating isovolumic left ventricle. Amer J Physiol 199:1115, 1960

[37] Pace JB. Priola DV, Randall WC. Alterations in cardiac synchrony and contractility during induced pulsus alternans. Physiologist 1966;9:259

[38] Hogancam C., Kardesch M, Danforth WH, Bing RJ. Transmembrane electrical potentials in ventricular tachycardia and fibrillation. Amer Heart J 1959;57: 214

[39] Cohn KE, Sandler H, Hancock W. Mechanisms of pulsus alternans Circulation 1967; 36: 372-380.

[40] Sugawara M, Niki K, Ohte N, Okada T, Harada A. Clinical usefulness of wave intensity analysis. Med Biol Eng Comput. 2009;47:197-206.

[41] Siniawski H, Unbehaun A, Lehmkuhl H, Kapell S, Schoen F, Hetzer R. Clinical and echocardiographic features in patients with dilated cardiomyopathy: Wave intensity and diastolic abnormality analysis. Przeglad Lekarski 2002;59(8):562-67

[42] Siniawski H, Heizmann P, Lehmkuhl HB, Dandel M, Hoffmann M, Knosalla C, Pasic M, Weng Y, Stein J, Hetzer R. Echocardiographic features of early graft dysfunction after heart transplantation. 2006 World Transplant Congress, Boston, 22.-27.7.2006. American Journal of Transplantation 2006;6(Suppl 2):557

[43] Vasan SR, Levy D. Defining diastolic heart failure: A call for standardized diagnostic criteria. Circulation 2000;101:2118-21

[44] Working Group Report. How to diagnose diastolic heart failure: European Study Group on Diastolic Heart Failure. Eur Heart J. 1998;19:990-1003

[45] Petrie CJ, Robertson M, Voors AJ, Van Veldhuisen AD, Dargie HJ. Abstract 2615: A low pulse pressure predicts mortality in patients with left ventricular dysfunction post myocardial infarction, but only in those with signs and symptoms of heart failure. Circulation 2007; 116: II 579

[46] Van Vliet BN, Montaini JP. Baroreflex stabilization of the double product. Am J Physiol. 1999;277:H1679-89 
[47] Niki K, Sugawara M, Chang D, Harada A, Okada T, Sakai R, Uchida K, Tanaka R, Mumford CE. A new noninvasive measurement system for wave intensity: evaluation of carotid arterial wave intensity and reproducibility. Heart Vessels 2002;17:12-2

[48] Burkhoff D, Maurer MS, Packer M. Heart failure with a normal ejection fraction: is it really a disorder of diastolic function? Circulation 2003;107:656-58

[49] Katz AM. The working heart, Ch 12. In: Katz AM Physiology of the Heart. Lippincott Williams and Wilkins, fifth edition 2011, pp. 313-42

[50] Yumino D, Redolfi S, Ruttanaumpawan P, Su MC, Smith S, Newton, GE, Mak S, Bradley TD. Nocturnal Rostral Fluid Shift: A Unifying Concept for the Pathogenesis of Obstructive and Central Sleep Apnea in Men With Heart Failure. Circulation 2010; 121; 1598-1605

[51] Jones C.J.H, Sugawara M, Kondoh Y, Uchida K, Parker K.H. Compression and expansion wavefront travel in canine ascending aortic flow: Wave intensity analysis. Heart Vessels 2002;16:91-98 


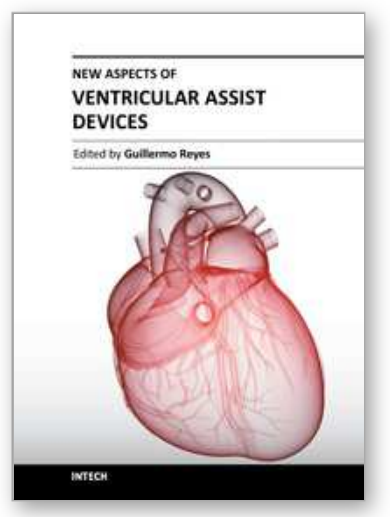

\author{
New Aspects of Ventricular Assist Devices \\ Edited by Dr. Guillermo Reyes
}

ISBN 978-953-307-676-8

Hard cover, 134 pages

Publisher InTech

Published online 29, August, 2011

Published in print edition August, 2011

Ventricular assist device has become one of the standard therapies for the support and the management of the failing heart. Updating our knowledge about these devices is mandatory in order to improve patient outcomes. In this book we can read the efforts made by many physicians concerned with the treatment of heart failure with mechanical devices. We all hope that the information compiled by experts in ventricle assist devices in this book will help us all to do better our main task - heal patients.

\title{
How to reference
}

In order to correctly reference this scholarly work, feel free to copy and paste the following:

Henryk Siniawski and Roland Hetzer (2011). Importance of Arterial Conduit Function Assessment in Chronic Congestive Heart Failure: Predictors of True Circulatory Decompensation for Optimal Timing of Mechanical Circulatory Support, New Aspects of Ventricular Assist Devices, Dr. Guillermo Reyes (Ed.), ISBN: 978-953307-676-8, InTech, Available from: http://www.intechopen.com/books/new-aspects-of-ventricular-assistdevices/importance-of-arterial-conduit-function-assessment-in-chronic-congestive-heart-failure-predictors-of

\section{INTECH}

open science | open minds

\section{InTech Europe}

University Campus STeP Ri

Slavka Krautzeka 83/A

51000 Rijeka, Croatia

Phone: +385 (51) 770447

Fax: +385 (51) 686166

www.intechopen.com

\section{InTech China}

Unit 405, Office Block, Hotel Equatorial Shanghai

No.65, Yan An Road (West), Shanghai, 200040, China

中国上海市延安西路65号上海国际贵都大饭店办公楼 405 单元

Phone: +86-21-62489820

Fax: +86-21-62489821 
(C) 2011 The Author(s). Licensee IntechOpen. This chapter is distributed under the terms of the Creative Commons Attribution-NonCommercialShareAlike-3.0 License, which permits use, distribution and reproduction for non-commercial purposes, provided the original is properly cited and derivative works building on this content are distributed under the same license. 